\title{
Cognitive Dysfunction in Patients With Rapid Eye Movement Dependent and Other Types of Obstructive Sleep Apnea Syndrome
}

\author{
Ece Yazlaa, d, Mustafa Bilici ${ }^{b}, Z^{a}$ errin Pelin ${ }^{c}$
}

\begin{abstract}
Background: Some cognitive functions have shown to be impaired in patients with obstructive sleep apnea syndrome (OSAS); however, differences between substypes have not been investigated yet. We aim to compare patients with rapid eye movement (REM) dependent sleep apnea syndrome (ROSAS) and control OSAS (COSAS) with regard to the impairment in cognitive functions and several sleep parameters.

Methods: Fifty COSAS and 20 ROSAS patients who met the inclusion criteria and diagnosed via polysomnographic examination were assessed using a data collection form and several scales.

Results and conclusion: No significant statistical difference was detected between groups regarding cognitive functions. The findings indicate that the cognitive function impairments in OSAS do not get more significant with the intensifying of the abnormal respiratory functions in REM periods.
\end{abstract}

Keywords: Obstructive sleep apnea syndrome; Cognitive functions; REM dependent obstructive sleep apnea

\section{Introduction}

The correlation between sleep and cognitive functions has long been attracting attention. Studies on healthy individuals indicate that sleep deprivation has negative effects on cognitive functions, particularly the working memory and attention $[1,2]$. These findings suggest that cognitive functions are impaired in sleep pathologies as well. As a matter of fact, there are studies demonstrating the negative effects of several sleep

Manuscript accepted for publication December 24, 2015

${ }^{a}$ Department of Psychiatry, Hitit University Corum Education and Research Hospital, Corum, Turkey

${ }^{\mathrm{b}}$ Department of Psychology, Istanbul Gelisim University, Istanbul, Turkey

'Academy of Health Science, Gaziantep, Turkey

${ }^{\mathrm{d} C}$ Corresponding Author: Ece Yazla, Department of Psychiatry, Hitit University

Faculty of Medicine, Corum, Turkey. Email: eceyazla@yahoo.com

doi: http://dx.doi.org/10.14740/jnr363w disorders such as restless leg syndrome, insomnia and rapid eye movement (REM) sleep behavioral disorders on the cognitive functions [3-7].

Obstructive sleep apnea syndrome (OSAS) is one of the most frequent sleep disorders that cause impairment in the structure of sleep [8]. Therefore, it is expected that cognitive functions may be impaired more than those observed in other sleep disorders. In fact, many studies have demonstrated that the cognitive functions are impaired in patients with OSAS $[9,10]$. The functional disorders which are related to OSAS have been determined to be attention [11], executive functions $[12,13]$ and working memory [14]. However, the patients with OSAS have been evaluated as a homogeneous population in these studies, and the cognitive functions in different OSAS groups have not been investigated. Recently, it was considered that OSAS may have sub-types and there may be differences in the clinical and laboratory findings of these sub-types [15-17]. These subtypes include positional, REM dependent, NREM dependent and stage independent [18-20].

As it is known, REM sleep is closely related to cognitive functions such as memory, attention, executive functions and dreaming. Cognitive function impairment is observed in disorders such as REM sleep behavior disorder, narcolepsy, nightmares and depression and in turn causes the impairment of REM sleep [6, 7, 21-23]. Furthermore, impairment in several cognitive functions has been demonstrated in patients using antidepressant or sedative drugs that suppress REM sleep [24-26]. These findings indicate that sleep disorders and drugs can cause abnormalities in cognitive functions via impairing the REM period of sleep. Therefore, further impairment is expected in patients with REM dependent OSAS (ROSAS) than those with non-dependent OSAS.

The aim of this study was to compare the cognitive functions of patients with REM dependent and REM non-dependent OSAS. The basic hypothesis of the study is that cognitive impairment in patients with REM dependent OSAS should be more prominent than that of the non-dependent group.

\section{Methods}

\section{Participants}

Twenty and 50 patients who applied to the Sleep Disorders 
Clinics of Erenkoy Neurolopsychiatric Diseases Education and Research Hospital between September 30, 2010 and August 25, 2011, and met the inclusion criteria of the study were included in the study. They were diagnosed polysomnographically (PSG) and clinically to have ROSAS and REM non-dependent control OSAS (COSAS) among 1,077 patients pre-diagnosed at the clinic as OSAS. Informed and written consents were obtained from patients that participated in the study.

ROSAS diagnosis was made based on the criteria of American Academy of Sleep Medicine (AASM 2007) [27], and the criteria of REM apnea hypopnea index (AHI)/nonREM AHI $\geq 2$ and non-REM AHI $<15$ [28]. Since cognitive functions may be impaired by the advance in age [29], elderly patients over 75 years of age were excluded from the study. Patients with diagnosis of psychiatric or neurologic disorders or receiving therapy for any of these ailments were excluded due to possible sleep or cognitive function alterations related to the diseases or the medication. Those with alcohol or drug abuse were excluded as well. Considering that partial improvement may be obtained in some cognitive functions by continuous positive airway pressure (CPAP) therapy [30], patients with a history of CPAP usage were also excluded. Fifty patients with COSAS and 20 patients with ROSAS who met the inclusion and exclusion criteria were informed about the study, and written informed consents were obtained.

In order to calculate the required number of patients to be included in the study, the standard deviations observed in the cognitive function levels of both groups and the difference between their mean levels would have to be predicted. However, there is no reliable medical literature information regarding this subject, no prediction could be made, and therefore precalculation of the patient count could not be made prior to the study. "Random sampling" method was used as the sampling method in determining the patient count. Our study included a total of 70 patients with OSAS including 21 female, 49 male patients aged between 25 and 71 years, and mean age of 49.04 \pm 11.67 years. The mean age of the patients with ROSAS $(\mathrm{n}=$ 20) was $53.45 \pm 11.61$, female to male ratio was $11 / 9$, the mean age of the patients with COSAS $(n=50)$ was $47.28 \pm 11.33$, and the female to male ratio was 10/40.

\section{PSG}

PSG examination included six channels of electroencephalogram (EEG) as C4-A1, C3-A2, O2-A1, O1-A2, F4-A1, and F3-A2 where the electrodes were placed in accordance with the international 10 - 20 montage system: two channels of electrooculography (EOG) for the monitorization of the left and right eye movements, temporal electromyography (EMG), anterior tibialis EMG, oro-nasal air flow via nasal cannula, arterial oxygen saturation, respiratory stress test via chest and abdomen bands, ECG and video monitorization recordings. REM logic was the software for the PSG. Scoring and reporting were performed according to the directives of AASM. The N7000 instrument that we used in the multi-directional data collection procedure is a comphrehensive PSG ampli- fier that has 32 channels of admissional property. PSG reports were prepared by the supervisor clinicians within the unit and included the following data: date of recording, time of start and stop the recording, sleep latency, total duration of sleep, duration of sleep periods to the total duration of sleep ratio, and respiratory parameters. Duration in bed, total duration of sleep, sleep latency, REM latency, N1 percentage, N2 percentage, N3 percentage, REM percentage, AHI, mean duration of apnea, minimal oxygen saturation, oxygen desaturation index, maximal duration of apnea, periodic leg movements index and arousal index data were used in the statistical analysis in the form of PSG parameters. The arousal index was obtained by summing of leg movements index and AHI.

\section{Data collection form}

This form includes sociodemographic data such as age, gender, maritial status, education qualification, occupational status, body mass index, waist circumference, neck circumference, time needed to fall asleep and the net time of sleep during the night within the last month.

\section{Epworth sleepiness scale}

It was developed by Johns in 1991 [31]. It is a scale that numerically determines the degree of sleepiness during daily activities within a month. The validity and reliability studies of the scale to its Turkish version were conducted by Agargun et al in 1999 [32]. This scale asks the patients to grade themselves between 0 and 3 in eight different situations during the daytime: 0 means that the person never feels asleep and 3 means that the person always feels asleep during the mentioned circumstances. The scale may result in a score between 0 and 24, and scores over 7 indicate the feeling of sleepiness.

\section{Serial digit learning test}

It was developed by Zangwill [33]. The validity and reliability studies of the test to its Turkish form were conducted by Karakas et al [34]. It is a test that measures learning ability and short term memory. In the test, there are two separate series of digits containing 8 and 9 digits respectively from 1 to 9 . One of these series is chosen according to the age and educational status of the individual. The numbers in the chosen series are read to the individuals and subsequently the participants are requested to remember the numbers in the right order. The test ends after 12 episodes or when the participant is able to remember two consecutive numbers. The number of episodes when learning is completed and total scores are noted. The test is sensitive to mesial temporal and hippocampal damages including Alzheimer's disease as well. However, the results of studies conducted by Larrabee and Curtiss using various memory and information processing scales suggested that digit span test was related to attention and information process rather than general 
Table 1. Comparison of Sociodemographic Characteristics of the Groups

\begin{tabular}{|c|c|c|c|c|c|c|}
\hline & \multicolumn{2}{|c|}{ ROSAS, mean \pm SD $(n=20)$} & \multicolumn{2}{|c|}{ COSAS, mean \pm SD $(n=50)$} & \multirow{2}{*}{$\mathbf{t} / \chi^{2}$} & \multirow{2}{*}{$\mathbf{P}$} \\
\hline & n & $\%$ & n & $\%$ & & \\
\hline \multicolumn{7}{|l|}{ Gender } \\
\hline Woman & 11 & 52.4 & 10 & 47.6 & 8.33 & $0.00 *$ \\
\hline Man & 9 & 18.4 & 40 & 81.6 & & \\
\hline \multicolumn{7}{|l|}{ Marital status } \\
\hline Single & 1 & 5 & 2 & 4 & 1.98 & 0.57 \\
\hline Married & 14 & 70 & 42 & 84 & & \\
\hline Widowed & 2 & 10 & 2 & 4 & & \\
\hline Divorced & 3 & 15 & 4 & 8 & & \\
\hline \multicolumn{7}{|l|}{ Education qualification } \\
\hline Elementary education & 9 & 45 & 23 & 46 & 0.33 & 0.84 \\
\hline High school & 3 & 15 & 10 & 20 & & \\
\hline \multirow[t]{2}{*}{ College } & 8 & 40 & 17 & 34 & & \\
\hline & Mean \pm SD & & Mean \pm SD & & $\mathrm{t}$ & $\mathrm{P}$ \\
\hline Age & $53.45 \pm 11.61$ & & $47.28 \pm 11.33$ & & 2.04 & $0.05^{*}$ \\
\hline Height & $165.7 \pm 9.56$ & & $170.66 \pm 7.64$ & & -2.27 & $0.02 *$ \\
\hline Weight & $84.75 \pm 13.60$ & & $91.14 \pm 17.82$ & & -1.44 & 0.15 \\
\hline Body mass index & $31.02 \pm 5.64$ & & $31.27 \pm 4.96$ & & -0.18 & 0.85 \\
\hline Neck circumference & $38.92 \pm 3.85$ & & $41.45 \pm 4.04$ & & -2.39 & $0.02 *$ \\
\hline Waist circumference & $103.85 \pm 11.07$ & & $109.4 \pm 14.65$ & & -1.52 & 0.13 \\
\hline
\end{tabular}

SD: standard deviation. ${ }^{*} \mathrm{P}<0.05$ values found statistically significant.

memory [35].

\section{Stroop test}

The original form of the Stroop test which has many variations was developed by Stroop in 1935 [35]. Stroop test is based on the finding that saying the colors of colored squares and circles takes longer time than reading words, and saying the names of the words written in different colors than actual meaning of the words takes longer time. Although there are different applications and scorings, the main model depends on reading the words written in different colors than their actual meanings and subsequently saying the color of the word it was written. The duration it took the participant to complete each task and the participant tendency of reading the meaning of the word rather than saying the color with which the word is written is noted. Because of the fact that the last mission necessitates dealing with various difficulties such as coping with the tendency for competitive answers, inhibiting the urge to give improper answers and sustaining selective attention patiently, it is sensitive to frontal lobe damages. The standardization of this test to suit the Turkish society was performed in the content of neuropsychological test for cognitive potentials (BILNOT Bataryasi) and the Turkish form of Stroop test was named as TUBITAK Basic Sciences Investigation Group (TBAG) Form [34]. The main basic structure of this test made up of five sec- tions follows the model of all Stroop tests. An increase was observed in the norm values of the Stroop test calculated for the Turkish population according to advanced age and educational status.

\section{Trail making test}

It was first developed as a part of an "Army Individual Test Battery" by the psychologs of the United States Army as visual-motor and visual-conseptional trail making test in 1944, and was presented to civil use in the following years [36]. Standardization to Turkish population was performed by samples of 50 years old or older [37]. It is an easy-to-use test which is sensitive to frontal lobe functions and commonly used for the measurement of executive functions. It can measure working memory, visual scan, complex visual scan, motor functions related to the attentional rate, processing rate, rapid planning, consecution ability, problem solving, visual-motor trail making, visual spatial procedures, visual conseptional abilities, cognitive flexibility, set shift, mental flexibility and reactional inhibition. It is made up of A and B sections. In section A, the patient is given a paper that contains numbered 25 circles that are irregularly arranged. The patient is asked using a pen to draw lines connecting the circles in numeric order without holding the pen from the paper. In section B, both numbers and letters are arranged randomly within the circles in the same pa- 
Table 2. Comparison of Clinical Characteristics of the Groups

\begin{tabular}{lllll}
\hline Variables & ROSAS $(\mathbf{n}=\mathbf{2 0})$ & COSAS $(\mathbf{n}=\mathbf{5 0})$ & $\mathbf{t}$ & P \\
\hline Epworth & $7.85 \pm 5.97$ & $8.82 \pm 4.68$ & -0.72 & 0.47 \\
Total time analyzed & $413.24 \pm 2287$ & $422.49 \pm 22.98$ & -1.52 & 0.13 \\
Total sleep time & $357.63 \pm 65.56$ & $373.14 \pm 47.59$ & -1.10 & 0.27 \\
Sleep latency & $11.11 \pm 12.33$ & $8.5 \pm 7.69$ & 1.07 & 0.28 \\
REM latency & $128.5 \pm 93.97$ & $153.47 \pm 91.62$ & -1.01 & 0.31 \\
Arousal index & $17.33 \pm 12.47$ & $61.35 \pm 38.76$ & -4.95 & $0.00^{*}$ \\
N1\% & $3.51 \pm 2.11$ & $4.82 \pm 3.01$ & -1.78 & 0.07 \\
N2\% & $59.87 \pm 16.16$ & $82.81 \pm 74.08$ & -1.36 & 0.17 \\
N3\% & $23.36 \pm 15.82$ & $16.25 \pm 18.67$ & 1.49 & 0.13 \\
REM\% & $13.17 \pm 4.57$ & $8.25 \pm 6.28$ & 3.17 & $0.00^{*}$ \\
AHI & $11.33 \pm 3.82$ & $37.23 \pm 27.04$ & -4.24 & $0.00^{*}$ \\
Mean apnea duration & $20.46 \pm 4.29$ & $24.13 \pm 5.72$ & -2.58 & $0.01 *$ \\
Lowest oxygen Saturation & $81.85 \pm 7.48$ & $77.75 \pm 10.34$ & 1.60 & 0.11 \\
Oxygen desaturation index & $9.63 \pm 4.95$ & $35.73 \pm 26.46$ & -4.36 & $0.00^{*}$ \\
Periodic limb movements index & $6.01 \pm 11.35$ & $24.10 \pm 26.59$ & -2.92 & $0.00^{*}$ \\
Longest apnea duration & $48.74 \pm 18.2$ & $61.62 \pm 19.93$ & 0.01 & 0.99 \\
\hline
\end{tabular}

${ }^{*} \mathrm{P}<0.05$ values found statistically significant.

per. The patient is asked to match the circles in numeric and alphabetical orders each time orders change. In section B which is accepted as the indicator of executive functions, the preservation mistakes may direct the patient to connect only the numbers or letters [38]. In our study, the timing and mistake numbers are evaluated in section B. This test was preferred in our study since it measures problem solving, arranging and visual spatial procedures along with the cognitive functions measured by Stroop test.

\section{Three words three shapes test}

The original form of the test is developed in order to evaluate the learning, memory, re-call and remembering functions of the elderly patients at their bedsides [38]. The standardization study for Turkish population and validity reliability study were designed for a shorter form of the test. Age and educational status were found to be correlated to the test scores [39]. In this short form which we used in our study, copying, instant memory, 15 min delayed memory and re-calling processes are evaluated via three shapes and three words. The shape and word scores are ranged between 0 and 15 for each of these processes.

\section{Statistical analysis}

The statistical analyses of this study were performed using Statistical Package for the Social Sciences (SPSS) program package, version 18. Chi-square test was used for the comparison of the sociodemographic characteristics of the groups. Descriptive statistics (mean, standard deviation) and also independent samples $t$-test were used for the comparison of the polysomnographical parameters and the scores of the tests evaluating age and cognitive functions. Pearson correlation analysis was used for investigating the correlation of clinical properties to each other. Values were expressed as mean \pm standard deviation. A P value $<0.05$ was accepted as statistically significant.

\section{Results}

\section{Comparison of the sociodemographic parameters}

Comparison of the mean ages, genders, maritial status, education years, occupational status, and the body mass index, waist and neck circumference measurements, time needed to fall asleep and the net duration of sleep during the night within the last month of the patients with ROSAS and COSAS are shown in Table 1. As seen in the table, ROSAS group included more females, whereas COSAS group included more males. This difference between the genders was statistically significant $(\mathrm{P}$ $<0.05)$. The height and neck circumference measurements of the participants in the COSAS group were higher than the participants in the ROSAS group which was statistically significant as well. The details are shown in Table 1.

\section{Comparison of the clinical variables between groups}

Comparison of the clinical variables between groups is shown in Table 2. The percentage of the REM period to total duration of sleep was found to be significantly higher in the ROSAS group $(\mathrm{t}=3.17, \mathrm{P}=0.00)$. In the COSAS group among the 
Table 3. Comparison of Cognitive Functions of the Groups

\begin{tabular}{lllll}
\hline Variables & ROSAS $(\mathbf{n}=\mathbf{2 0})$ & COSAS $(\mathbf{n}=\mathbf{5 0})$ & $\mathbf{Z}$ & $\mathbf{P}$ \\
\hline Stroop subtask 1 speed & 37.05 & 34.88 & -0.40 & 0.68 \\
Stroop subtask 3 speed & 35.05 & 35.68 & -0.11 & 0.90 \\
Stroop subtask 5 speed & 35.3 & 35.88 & -0.05 & 0.95 \\
Interference & 35.7 & 35.42 & -0.05 & 0.95 \\
Serial digit learning test & 33.45 & 36.32 & -0.53 & 0.59 \\
Trail making test speed & 35.8 & 35.38 & -0.07 & 0.93 \\
Trail making test error & 39.85 & 33.76 & -1.21 & 0.22 \\
TWTS copy shape & 35.08 & 35.67 & -0.18 & 0.85 \\
TWTS copy word & 35.5 & 35.5 & 0.00 & 1.00 \\
TWTS incidental recall shape & 36.6 & 35.06 & -0.30 & 0.76 \\
TWTS incidental recall word & 34.38 & 35.95 & -0.31 & 0.75 \\
TWTS delayed recall shape & 35.3 & 35.58 & -0.06 & 0.95 \\
TWTS delayed recall word & 32.58 & 36.67 & -0.81 & 0.41 \\
TWTS recognition shape & 36 & 35.3 & 0.63 & 0.52 \\
TWTS recognition word & 32.3 & 36.78 & -1.31 & 0.18 \\
\hline
\end{tabular}

TWTS: Three Words Three Shapes. * $\mathrm{P}<0.05$ values found statistically significant.

variables that define the severity of the disease arousal index $(\mathrm{t}=-4.95, \mathrm{P}=0.00)$, AHI $(\mathrm{t}=-4.24, \mathrm{P}=0.00)$, mean duration of apnea $(\mathrm{t}=-2.58, \mathrm{P}=0.01)$, oxygen desaturation index $(\mathrm{t}=$ $-4.36, P=0.00)$ and periodic leg movements index $(t=-2.92$, $\mathrm{P}=0.00)$.

Comparison of the cognitive functions between groups is shown in Table 3. No significant difference was observed between groups regarding the cognitive functions.

\section{Correlation of the variables to each other}

When all patients were evaluated as a whole, significant correlations were observed between three shapes three words test and N3\% $(\mathrm{r}=-0.40, \mathrm{P}=0.00)$, Stroop section 1 rate and $\mathrm{N} 2 \%(\mathrm{r}=0.52, \mathrm{P}=0.00)$ and N3\% $(\mathrm{r}=0.41, \mathrm{P}=0.00)$, Stroop section 5 rate and periodic limb movement (PLM) index ( $\mathrm{r}=$ $0.33, \mathrm{P}=0.00)$ and Stroop impairing effect and PLM index ( $\mathrm{r}$ $=0.323, \mathrm{P}=0.007)$.

When the ROSAS group is evaluated alone, significant correlations were observed between three shapes three words test and the period spent in bed $(\mathrm{r}=0.45, \mathrm{P}=0.04)$, Stroop section 1 rate and $\mathrm{N} 2 \%(\mathrm{r}=-0.47, \mathrm{P}=0.03), \mathrm{N} 3 \%(\mathrm{r}=0.47, \mathrm{P}=0.03)$, AHI $(r=0.54, P=0.01)$, minimal oxygen saturation $(r=-0.48$, $\mathrm{P}=0.03)$ and oxygen desaturation index $(\mathrm{r}=0.51, \mathrm{P}=0.02)$.

When the COSAS group is evaluated alone, significant correlations were observed between the digit span test scores and sleep latency $(\mathrm{r}=-0.42, \mathrm{P}=0.00)$ and $\mathrm{N} 2 \%(\mathrm{r}=-0.28, \mathrm{P}$ $=0.04)$, trail making test and total duration of sleep $(\mathrm{r}=-0.28$, $\mathrm{P}=0.04)$, minimal oxygen saturation $(\mathrm{r}=-0.32, \mathrm{P}=0.02)$ and maximal duration of apnea $(\mathrm{r}=0.29, \mathrm{P}=0.04)$. Furthermore, significant correlations were observed between three shapes three words test incidental recall and N2\% $(\mathrm{r}=-0.30, \mathrm{P}=0.03)$ and $\mathrm{N} 3 \%(\mathrm{r}=-0.44, \mathrm{P}=0.00)$; three shapes three words test delayed shape and N2\% $(r=-0.32, P=0.02)$, three shapes three words test recognition word and PLM index $(r=-0.36, P$ $=0.01)$, Stroop section 1 speed and N2\% $(\mathrm{r}=0.59, \mathrm{P}=0.00)$ and N3\% $(r=0.42, P=0.00)$, Stroop section 5 speed and total duration of sleep $(r=-0.29, P=0.04)$ and PLM index $(r=0.35$, $\mathrm{P}=0.01)$; Stroop interference effect and total duration of sleep $(\mathrm{r}=-0.28, \mathrm{P}=0.04)$ and PLM index $(\mathrm{r}=0.34, \mathrm{P}=0.01)$.

\section{Discussion}

In this study, the cognitive functions of the patients with ROSAS whose apneas are usually observed in the REM period and patients with COSAS whose apneas are observed in all periods of sleep were compared. Furthermore, the possible correlations of various sociodemographic characteristics and clinical properties to the cognitive functions were investigated.

The most important findings of this study were as follows: 1) Among the patients with COSAS, sleep parameters such as arousal index, AHI, mean duration of apnea, oxygen desaturation index and PLM index were significantly higher. 2) No significant difference was observed between groups regarding the cognitive functions. 3) In the COSAS group, significant correlation was observed between the Stroop interference effect and PLM index.

It has been detected that the number of women was more among the ROSAS group and the number of men was more among the COSAS group which were both statistically significant. In a study investigating the effect of gender on the polysomnographic features of OSAS, the incidence of ROSAS was detected to be more frequent than COSAS [28]. In another study on ROSAS, it was detected to be more frequent among women than men $[40,41]$. The protection of young women from COSAS despite obesity was explained with age- 
dependent differences in female hormones by some investigators [41]. Since the present information does not present an evidence on the reduction of COSAS by estrogen or progesterone hormones, it has been postulated that the development of ROSAS was related to a harder and younger airway rather than the female hormones [40]. Our findings support the findings in these literatures. Observation of ROSAS among women more frequently may be explained by the effects of female hormonal or anatomic differences to airways.

It was observed that the neck circumferences of the patients with COSAS were longer than those with ROSAS. No previous study has been done regarding this finding. In a study on ROSAS, each five units of increase in the body mass index were observed to be related to the increase in the frequency of NREM apneas [41]. In two other studies, patients with ROSAS were detected to be more obese $[19,40]$. The comment of our findings is controversial; however, when evaluating the obesity measurements on the basis of these findings, neck circumference among patients with COSAS may be evaluated as a more important risk factor than waist circumference or body mass index.

No difference was observed between groups regarding Epworth scale scores. Similarly, in a previous study comparing the clinical characteristics of patients with ROSAS to those with OSAS, no difference was observed between the scores of Epworth scale [19]. In another study, no correlation was detected between the scores of Epworth scale and REM AHI measurements [42]. The extreme daily sleepiness observed frequently in patients with OSAS may be due to the severity of respiratory parameters or arousals that impair the uniformity of sleep. However, it may be understood that observation of the respiratory events common in REM periods does not change the severity of sleepiness.

It was observed that the arousal index, AHI, oxygen desaturation index, PLM index and mean duration of apnea were higher in patients with COSAS than the patients with ROSAS. In the previous studies investigating the clinical properties of ROSAS, the disease was reported to be observed in patients with mild OSAS as well $[19,28]$. In another study investigating the duration of apneas and the severity of hypoxemia in REM periods of the patients with OSAS, it was determined that the apneas were longer in the REM periods and the decrease in oxygen saturation was much. This finding has been explained by the findings of irregular respiration in REM period compared to NREM period, less protected oxygen saturation and more reduced respiratory response to nocturnal hypoxemia which were reported in the previous studies [43]. The findings of our study do not support the previous findings. The possible reasons of this controversy may be the differences between the individuals in the oxygen saturation decrease in REM sleep or the limitations in the number of patients.

In the studies conducted in order to investigate the impairments in the cognitive functions in OSAS, the findings observed were various. However, the most frequently impaired cognitive functions in OSAS may be counted as attention, executive functions and working memory [44-46]. To our knowledge, there is no study investigating the impairment in the cognitive functions of the patients with OSAS whose apneas are predominantly observed during the REM sleep peri- ods or comparing the cognitive functions of this group to other patients with OSAS. Therefore, it may be said that our study is the first to investigate the subject. However, no statistically significant difference is observed between groups regarding the cognitive functions. This finding suggests that no additional impairing effect is observed on the cognitive functions since the abnormal respiratory events are predominantly observed in the REM period of the sleep.

When the correlation between the cognitive functions and other variables is investigated, a significant positive relation is detected between the Stroop impairing effect and PLM index in the COSAS group. It has been known that the PLM syndrome frequently accompanies OSAS; however, the clinical relation of this co-existence has not been investigated in details [47]. It has been demonstrated that the impairment in the structure of the sleep in both disorders may cause impairment in the short term memory and other cognitive problems [48, 49]. Furthermore, when it is considered that PLM, arousal index, AHI and oxygen desaturation index are all elevated in patients with COSAS, PLM index together with the impairment in other parameters impairs the structure of the sleep more and may result in the frontal lobe and executive functions where stroop test is sensitive.

The primary limitation of this study is the limited number of patients. The power of the number of patients admitted to our clinics is insufficient to proof our hypothesis. Therefore, the results obtained should be supported by larger sample sizes. The second limitation is that the neuropsychological tests that measure the cognitive functions of the patients were performed in different hours of the days. Although they were usually performed in the evening hours, some patients were not available at the defined hours and thus the tests were performed in the daytime for these patients. In a previous study investigating the daily differences in the executive functions of the patients with OSAS, it was determined that the impairments were more significant in the advanced hours of the days, and this was interpreted as the sircadien variation and the effect of awakefulness [45]. Therefore, it may be concluded that a study which performs these tests within the same range of time may give more clear results.

\section{Conclusion}

As a conclusion, this study suggests that the impairment in the cognitive functions and abnormal respiratory events in patients with OSAS does not become more significant in the REM period. Therefore, it may be concluded that the cognitive impairment in the patients is generally related to the impairment in the structure of the sleep. However, it should be mentioned that opinions such as hypoxia and arousals being the reason for the impairment in the cognitive functions as it was advocated in previous studies are controversial.

\section{Acknowledgement}

We thank the staff of the Sleep Disorders Clinics of Erenkoy 
Neurolopsychiatric Diseases Education and Research Hospital.

\section{Conflict of Interest}

None.

\section{Author Contributions}

Design of the study: Mustafa Bilici and Zerrin Pelin. Acquisition of data: Zerrin Pelin, Mustafa Bilici and Ece Yazla. Analysis and interpretation of data: Ece Yazla and Mustafa Bilici. Drafting of the manuscript: Ece Yazla and Mustafa Bilici. Critical revision of the manuscript for important intellectual content: Ece Yazla and Mustafa Bilici. Statistical analysis: Mustafa Bilici and Ece Yazla. Administrative, technical, and material support: Ece Yazla. Study supervision: Mustafa Bilici.

\section{References}

1. Pomplun M, Silva EJ, Ronda JM, Cain SW, Munch MY, Czeisler CA, Duffy JF. The effects of circadian phase, time awake, and imposed sleep restriction on performing complex visual tasks: evidence from comparative visual search. J Vis. 2012;12(7).

2. Jugovac D, Cavallero C. Twenty-four hours of total sleep deprivation selectively impairs attentional networks. Exp Psychol. 2012;59(3):115-123.

3. Fulda S, Schulz H. Cognitive dysfunction in sleep disorders. Sleep Med Rev. 2001;5(6):423-445.

4. Fulda S, Beitinger ME, Reppermund S, Winkelmann J, Wetter TC. Short-term attention and verbal fluency is decreased in restless legs syndrome patients. Mov Disord. 2010;25(15):2641-2648.

5. Drummond SP, Walker M, Almklov E, Campos M, Anderson DE, Straus LD. Neural correlates of working memory performance in primary insomnia. Sleep. 2013;36(9):1307-1316.

6. Nardone R, Bergmann J, Kunz A, Christova M, Brigo F, Tezzon F, Trinka E, et al. Cortical afferent inhibition is reduced in patients with idiopathic REM sleep behavior disorder and cognitive impairment: a TMS study. Sleep Med. 2012;13(7):919-925.

7. Iranzo A, Isetta V, Molinuevo JL, Serradell M, Navajas D, Farre R, Santamaria J. Electroencephalographic slowing heralds mild cognitive impairment in idiopathic REM sleep behavior disorder. Sleep Med. 2010;11(6):534-539.

8. Viswanath A, Ramamurthy J, Dinesh SP, Srinivas A. Obstructive sleep apnea: awakening the hidden truth. Niger J Clin Pract. 2015;18(1):1-7.

9. Gagnon K, Baril AA, Gagnon JF, Fortin M, Decary A, Lafond C, Desautels A, et al. Cognitive impairment in obstructive sleep apnea. Pathol Biol (Paris). 2014;62(5):233240.

10. Engleman HM, Kingshott RN, Martin SE, Douglas NJ.
Cognitive function in the sleep apnea/hypopnea syndrome (SAHS). Sleep. 2000;23(Suppl 4):S102-108.

11. Verstraeten E, Cluydts R. Executive control of attention in sleep apnea patients: theoretical concepts and methodological considerations. Sleep Med Rev. 2004;8(4):257267.

12. Saunamaki T, Jehkonen M. A review of executive functions in obstructive sleep apnea syndrome. Acta Neurol Scand. 2007;115(1):1-11.

13. Borges JG, Ginani GE, Hachul H, Cintra FD, Tufik S, Pompeia S. Executive functioning in obstructive sleep apnea syndrome patients without comorbidities: focus on the fractionation of executive functions. J Clin Exp Neuropsychol. 2013;35(10):1094-1107.

14. Prilipko O, Huynh N, Schwartz S, Tantrakul V, Kim JH, Peralta AR, Kushida C, et al. Task positive and default mode networks during a parametric working memory task in obstructive sleep apnea patients and healthy controls. Sleep. 2011;34(3):293-301A.

15. Haba-Rubio J, Janssens JP, Rochat T, Sforza E. Rapid eye movement-related disordered breathing: clinical and polysomnographic features. Chest. 2005;128(5):3350-3357.

16. Siddiqui F, Walters AS, Goldstein D, Lahey M, Desai H. Half of patients with obstructive sleep apnea have a higher NREM AHI than REM AHI. Sleep Med. 2006;7(3):281285.

17. Muraki M, Kitaguchi S, Ichihashi H, Haraguchi R, Iwanaga T, Kubo H, Higashiyama A, et al. Apnoea-hypopnoea index during rapid eye movement and non-rapid eye movement sleep in obstructive sleep apnoea. J Int Med Res. 2008;36(5):906-913.

18. Liu Y, Su C, Liu R, Lei G, Zhang W, Yang T, Miao J, et al. NREM-AHI greater than REM-AHI versus REMAHI greater than NREM-AHI in patients with obstructive sleep apnea: clinical and polysomnographic features. Sleep Breath. 2011;15(3):463-470.

19. Campos-Rodriguez F, Fernandez-Palacin A, Reyes-Nunez N, Reina-Gonzalez A. [Clinical and polysomnographic features of rapid-eye-movement-specific sleep-disordered breathing]. Arch Bronconeumol. 2009;45(7):330-334.

20. Gupta R, Lahan V, Sindhwani G. Sleep-stage-independent obstructive sleep apnea: an unidentified group? Neurol Sci. 2013;34(9):1543-1550.

21. Ha KS, Yoo HK, Lyoo IK, Jeong DU. Computerized assessment of cognitive impairment in narcoleptic patients. Acta Neurol Scand. 2007;116(5):312-316.

22. Simor P, Pajkossy P, Horvath K, Bodizs R. Impaired executive functions in subjects with frequent nightmares as reflected by performance in different neuropsychological tasks. Brain Cogn. 2012;78(3):274-283.

23. Galecki P, Talarowska M, Moczulski D, Bobinska K, Opuchlik K, Galecka E, Florkowski A, et al. Working memory impairment as a common component in recurrent depressive disorder and certain somatic diseases. Neuro Endocrinol Lett. 2013;34(5):436-445.

24. Watts A, Gritton HJ, Sweigart J, Poe GR. Antidepressant suppression of non-REM sleep spindles and REM sleep impairs hippocampus-dependent learning while augmenting striatum-dependent learning. J Neurosci. 
2012;32(39):13411-13420.

25. Bridoux A, Laloux C, Derambure P, Bordet R, Monaca Charley $\mathrm{C}$. The acute inhibition of rapid eye movement sleep by citalopram may impair spatial learning and passive avoidance in mice. J Neural Transm (Vienna). 2013;120(3):383-389.

26. Pagel JF, Parnes BL. Medications for the Treatment of Sleep Disorders: An Overview. Prim Care Companion J Clin Psychiatry. 2001;3(3):118-125.

27. The AASM manual for the scoring of sleep and associated events: rules, terminology, and technical specification, 2007.

28. O'Connor C, Thornley KS, Hanly PJ. Gender differences in the polysomnographic features of obstructive sleep apnea. Am J Respir Crit Care Med. 2000;161(5):14651472.

29. Vanguilder HD, Bixler GV, Sonntag WE, Freeman WM. Hippocampal expression of myelin-associated inhibitors is induced with age-related cognitive decline and correlates with deficits of spatial learning and memory. J Neurochem. 2012;121(1):77-98.

30. Ferini-Strambi L, Baietto C, Di Gioia MR, Castaldi P, Castronovo C, Zucconi M, Cappa SF. Cognitive dysfunction in patients with obstructive sleep apnea (OSA): partial reversibility after continuous positive airway pressure (CPAP). Brain Res Bull. 2003;61(1):87-92.

31. Johns MW. A new method for measuring daytime sleepiness: the Epworth sleepiness scale. Sleep. 1991;14(6):540545 .

32. Agargun MY, Cilli AS, Kara H, Bilici M, Telcioglu M, Semiz UB, Basoglu C. Epworth Uykululuk Olcegi'nin Gecerliligi ve Guvenilirligi. Turk Psikiyatri Dergisi. 1999;10:261-267.

33. Zangwill OL. Clinical Tests of Memory Impairment. Proc R Soc Med. 1943;36(11):576-580.

34. Karakas S, Eski R, Basar E. Turk kulturu icin standardizasyonu yapilmis bir noropsikolojik testlert toplulugu: BILNOT Bataryasi. 32. Ulusal Noroloji Kongresi Kitabi, Istanbul. 1996;43-70.

35. Larrabee GJ, Curtiss G. Construct validity of various verbal and visual memory tests. J Clin Exp Neuropsychol. 1995; 17(4):536-547.

36. Reitan RM. The relation of the trail making test to organic brain damage. J Consult Psychol. 1955;19(5):393-394.

37. Cangoz B, Karakoc E, Selekler K. Iz Surme Testi'nin 50 yas ve uzeri Turk yetiskin ve yasli orneklemi icin standardizasyon calismasi. Turkish Journal of Geriatrics. 2007;10:73-82.

38. Weintraub S, Mesulam MM. Mental state assessment of young and elderly adults in behavioural neurology. Mesulam MM (Ed.), Principles of behavioral neurology. 4th Edition, Philadelphia: FA Davis, 1985, 71-123.

39. Kudiaki C, Aslan A. The Three Words-Three Shapes test: normative data for the Turkish elderly. Arch Clin Neuropsychol. 2007;22(5):637-645.

40. Koo BB, Dostal J, Ioachimescu O, Budur K. The effects of gender and age on REM-related sleep-disordered breathing. Sleep Breath. 2008;12(3):259-264.

41. Koo BB, Patel SR, Strohl K, Hoffstein V. Rapid eye movement-related sleep-disordered breathing: influence of age and gender. Chest. 2008;134(6):1156-1161.

42. Chami HA, Baldwin CM, Silverman A, Zhang Y, Rapoport D, Punjabi NM, Gottlieb DJ. Sleepiness, quality of life, and sleep maintenance in REM versus non-REM sleep-disordered breathing. Am J Respir Crit Care Med. 2010;181(9):997-1002.

43. Findley LJ, Wilhoit SC, Suratt PM. Apnea duration and hypoxemia during REM sleep in patients with obstructive sleep apnea. Chest. 1985;87(4):432-436.

44. Decary A, Rouleau I, Montplaisir J. Cognitive deficits associated with sleep apnea syndrome: a proposed neuropsychological test battery. Sleep. 2000;23(3):369-381.

45. Lis S, Krieger S, Hennig D, Roder C, Kirsch P, Seeger W, Gallhofer B, et al. Executive functions and cognitive subprocesses in patients with obstructive sleep apnoea. J Sleep Res. 2008;17(3):271-280.

46. Felver-Gant JC, Bruce AS, Zimmerman M, Sweet LH, Millman RP, Aloia MS. Working memory in obstructive sleep apnea: construct validity and treatment effects. J Clin Sleep Med. 2007;3(6):589-594.

47. Iriarte J, Alegre M, Irimia P, Urriza J, Artieda J. [Clinical relevance of periodic limb movements during sleep in obstructive sleep apnea patients]. Rev Neurol. 2000;30(2):101-104.

48. Gieteling EW, Bakker MS, Hoekema A, Maurits NM, Brouwer WH, van der Hoeven JH. Impaired driving simulation in patients with Periodic Limb Movement Disorder and patients with Obstructive Sleep Apnea Syndrome. Sleep Med. 2012;13(5):517-523.

49. Ehrenberg B. Importance of sleep restoration in comorbid disease: effect of anticonvulsants. Neurology. 2000;54(5 Suppl 1):S33-37. 